\title{
Do High-mobility Group Box 1 Gene Polymorphisms Affect the Incidence of Differentiation Syndrome in Acute Promyelocytic Leukemia?
}

Ghazaleh Hoseinzadeh

TUMS: Tehran University of Medical Sciences

Zahra Mohammadzadeh

TUMS: Tehran University of Medical Sciences

Bahram Chahardouli

TUMS: Tehran University of Medical Sciences

Kamran Ali Moghaddam

TUMS: Tehran University of Medical Sciences

Seyed Asadollah Mousavi

Tehran University of Medical Sciences

Azadeh Omidkhoda ( $\nabla$ a-omidkhoda@tums.ac.ir)

TUMS: Tehran University of Medical Sciences https://orcid.org/0000-0003-1320-1509

Shahrbano Rostami

TUMS: Tehran University of Medical Sciences

Research Article

Keywords: Acute Promyelocytic Leukemia, Differentiation syndrome, HMGB1, SNPs

Posted Date: December 2nd, 2021

DOI: https://doi.org/10.21203/rs.3.rs-1084766/v1

License: () (i) This work is licensed under a Creative Commons Attribution 4.0 International License. Read Full License 


\section{Abstract}

Differentiation syndrome (DS) is an inflammatory complication seen in some patients with acute promyelocytic leukemia (APL) undergoing differentiation therapy with all-trans retinoic acid (ATRA) and/or arsenic trioxide (ATO). It is unknown how DS occurs, but it is believed that it is caused by inflammatory cytokines release from differentiating leukemic cells. High mobility group box-1 (HMGB1) is a DNA-binding protein that acts as a cytokine outside of cells and may play a role in inflammation. This study was conducted to determine whether HMGB1 polymorphisms (rs1360485, rs2249825 and rs1060348) are associated with the incidence of differentiation syndrome in acute promyelocytic leukemia patients treated with all-trans retinoic acid and arsenic trioxide. One hundred and thirty APL patients and 100 healthy controls were included. Seventeen patients with differentiation syndrome were selected according to the PETHEMA criteria. Tetra-primer ARMS polymerase chain reaction (tetra-ARMS PCR) was used to determine the genotype distribution of polymorphisms. DNA sequencing was done to validate the results. In both healthy and APL patients, AA was the most frequent genotype in rs 1360485 followed by AG and GG. CC, CG, and GG were the most frequent genotypes in rs2249825 polymorphism in the order mentioned. CC was more frequent than CT, and CT was more frequent than TT in rs1060348. There was no correlation between HMGB1 polymorphisms and the incidence of differentiation syndrome based on genetic models ( $p-$ value $>0.05$ ). As a result, HMGB1 polymorphisms are not probably associated with DS development in APL patients treated with ATRA and ATO.

\section{Introduction}

Acute promylocytic leukemia (APL) is a distinct and rare subtype of acute myeloid leukemia accounting for $10-15 \%$ of all acute myeloid leukemias (AMLs) in a year [1]. In 90\% of cases, APL is characterized by the reciprocal translocation t $(15 ; 17)$ (q22; q21) (retinoic acid receptor-alpha (RARA) gene on chromosome 17 is involved in a translocation with the promyelocytic leukemia gene (PML) on chromosome 15$)$. $\mathrm{t}(15 ; 17)$ giving rise to a $P M L / R A R A$ gene fusion product which prevent the expression of genes involved in granulocytes proliferation and differentiation, cease the differentiation of myelocytes, and cause endless proliferation [2, 3]. The most effective drugs for APL treatment are All-trans retinoic acid (ATRA) and arsenic trioxide (As203). They induce PML/RARa chimeric oncoprotein degradation that causes the onset of APL cell differentiation and ceases neoplastic promyelocyte differentiation [4, 5]. APL was formerly considered one of the most fetal subtypes of AML, but treatment with arsenic trioxide and all-trans retinoic acid has improved the outcomes in recent years [6].

In some APL patients, ATRA and/or arsenic trioxide administration may results in a life-threatening complication that is called differentiation syndrome (DS) $[7,8]$. This complication occurs in massive leukemic blast presence not during consolidation or maintenance therapy. The main characteristic features of DS are: fever, acute respiratory distress with interstitial pulmonary infiltrates, and/or a vascular capillary leak syndrome leading to acute renal failure. These main symptoms may primarily cause by cellular migration, endothelial activation, release of interleukins, and vascular factors responsible for tissue damage [9, 10] Montesinos et al, reported $24.8 \%$ treated patients experienced DS, $12.6 \%$ were severe and $12.2 \%$ moderate cases. [11]. The pathogenesis of DS is not fully understood, but it is believed cytokines released from differentiating leukemic cells lead to systemic inflammatory response syndrome (SIRS) in DS [12, 13].

High mobility group box1 (HMGB1), also called amphoterin and p30, is a highly conserved protein that belongs to the HMGB family. It is extremely versatile and unique with extracellular and intracellular functions [14]. Inside cells, in the nucleus, it binds to the DNA with no sequence specificity and acts as a chaperon and regulates the transcription of various genes. However, it acts as a cytokine and may cause inflammation out of cells. Several studies have shown that HMGB1 polymorphisms play an important role in inflammatory diseases and cancer development [15-21]. It can also play role in hematopoietic malignancies like leukemia, lymphoma, myelodysplastic syndrome and multiple myeloma [22]. Several studies have shown that HMGB1 and its polymorphisms play important role in inflammatory diseases [14, 19, 21, 23, 24].

Due to the importance of HMGB1 gene variations and their role in inflammatory diseases, this study was conducted to assess the association between rs1360485, rs2249825, and rs1060348 polymorphisms of the HMGB1 gene and DS incidence in APL patients treated with ATRA and ATO.

\section{Materials And Methods}

\section{participants}

The Ethical Committee of Tehran University of Medical Sciences approved the study (IR.TUMS.SPH.REC.1397.271). This study was conducted on APL patients who presented to the Hematology, Oncology, and Stem Cell Transplantation Research Center of Shariati Hospital, Tehran, Iran from 2012 to 2017. Real-time PCR was done for the presence of $t(15 ; 17)$. One hundred and thirty APL patients were selected and informed consent was obtained from them. One hundred healthy volunteers were also included as controls. Seventeen patients with APL were diagnosed with differentiation syndrome according to the PETEHMA criteria (fever $\geq 38^{\circ} \mathrm{C}$, weight gain $>5 \mathrm{~kg}$, hypotension, dyspnea, LQTS (Long QT Syndrome) and acute renal failure after receiving ATRA/ATO).

\section{SNP selection}

Three SNPs including rs2249825 (3814C/G; genomic number 31,037,903) near the exon, rs1360485 (3'UTR, T/C; genomic number 31,031,884) in the 3' untranslated region, and rs1060348 (982 C > T) were selected based on previous studies and their effect on inflammatory diseases and cancers.

\section{DNA extraction}

The standard salting out method was used to extract DNA from peripheral blood samples. All samples were collected in tubes containing ethylene-diamine tetra acetic acid (EDTA). NanoDrop device (Thermo Fisher Scientific, USA) was used to evaluate the purity and concentration of the extracted DNA.

\section{Tetra-ARMS PCR and Validation assay}


Tetra ARMS polymerase chain reaction (Tetra-ARMS PCR) was used for detection of all HMGB1 polymorphisms. The primers are shown in (Table 1). The reaction was done in a total volume of $15 \mu$ lincluding optimum forward and reverse inner primer ratios for rs1360485, rs2249825 and rs1060348 (1:1, 1:2 and 2:1, respectively and 0.2-0.5 $\mu \mathrm{M}$ of each outer primer, template DNAs $(1 \mu \mathrm{l})(60-80 \mathrm{ng} / \mu \mathrm{l})$, Master Mix PCR (Ampliqon, Denmark) $(7.5 \mu \mathrm{l})$. The optimum PCR conditions for rs 1360485 , rs 2249825 and rs 1060348 were $94^{\circ} \mathrm{C}$ for $4 \mathrm{~min}\left(95^{\circ} \mathrm{C}\right.$ for $20 \mathrm{~s}, 60^{\circ} \mathrm{C}$ for $30 \mathrm{~s}$, and $72{ }^{\circ} \mathrm{C}$ for $\left.45 \mathrm{~s}\right) \times 35 \mathrm{cycles}$ and $72{ }^{\circ} \mathrm{C}$ for $7 \mathrm{~min}$; 95 ${ }^{\circ} \mathrm{C}$ for $3 \mathrm{~min}\left(95^{\circ} \mathrm{C}\right.$ for $15 \mathrm{~s}, 56^{\circ} \mathrm{C}$ for $20 \mathrm{~s}$, and $72^{\circ} \mathrm{C}$ for $\left.20 \mathrm{~s}\right) \times 32$ cycles and $72{ }^{\circ} \mathrm{C}$ for $6 \mathrm{~min}$; and $96{ }^{\circ} \mathrm{C}$ for 6 min $\left(96^{\circ} \mathrm{C}\right.$ for $20 \mathrm{~s}, 60^{\circ} \mathrm{C}$ for $30 \mathrm{~s}$, and $72{ }^{\circ} \mathrm{C}$ for $45 \mathrm{~s}) \times 32$ cycles and $72^{\circ} \mathrm{C}$ for $4 \mathrm{~min}$, respectively. DNA amplification results were validated by DNA sequencing as described previously [25].

Table 1. Designed primers sequence for tetra ARMS-PCR

\begin{tabular}{|c|c|c|c|}
\hline Polymorphism & Primer & Sequence & Product size (bp) \\
\hline \multirow[t]{4}{*}{ rs1360485 } & Forward inner primer (FI) & СTCTGTTATAGAATTGCTTGTTTCCCA & A allele (205bp) \\
\hline & Reverse inner primer (RI) & TGTTGTATGGTTATCTGTCATGATGTCTC & G allele (284bp) \\
\hline & Forward outer primer (FO) & TTGAATTTCTTTTCATATTTGTGCTTTG & \multirow[t]{2}{*}{ Control band (433bp) } \\
\hline & Reverse outer primer (RO) & AAATTCCACTAATTAGAAGGTCCAAACC & \\
\hline \multirow[t]{4}{*}{ rs2249825 } & Forward inner primer $(\mathrm{FI})$ & ATAACCAGTACTTTGGTTTTCATTGCC & C allele (245bp) \\
\hline & Reverse inner primer (RI) & GACATATAAGACCTTAAAGTACTTAGTTAC & G allele ( 293bp) \\
\hline & Forward outer primer (FO) & GGTGTTCTAGATTTTAAAATCGTTTAAG & \multirow[t]{2}{*}{ Control band (481bp) } \\
\hline & Reverse outer primer (RO) & СTTCTTAGAAAACTCTGAGAAGTTGACT & \\
\hline \multirow[t]{4}{*}{ rs1060348 } & Forward inner primer (FI) & TAATTTTTTTTTTAGTTCGGCCTTCGTC & C allele (189bp) \\
\hline & Reverse inner primer (RI) & TTGGGCGATACTCAGAGCAGAAGCGA & T allele (132bp) \\
\hline & Forward outer primer (FO) & TCACAGGCAGCTTTAAATAGCAATGCAG & \multirow[t]{2}{*}{ Control band (267bp) } \\
\hline & Reverse outer primer (RO) & TTTCATATTTTTCCTTCAGCTTCGCAGC & \\
\hline
\end{tabular}

\section{Statistical analysis}

Statistical analysis was performed as described previously [25].

\section{Results}

\section{Baseline characteristics}

One hundred and thirty APL patients (70 males and 60 females) and 100 healthy controls (47 males and 33 females) were studied. The mean age of the APL patients and control subjects was 36.5 and 36.9 years respectively, indicating no significant difference ( $P$ value $>0.05)$. The hematologic and laboratory findings of the APL patients with and without DS are presented in (Tables 2). The allele and genotype distribution of rs1360485, rs2249825 and rs1060348 did not deviate from the Hardy-Weinberg equilibrium in APL patients and normal subjects ( $P$ value $>0.05)$. Chi-square and Mann-Whitney $U$ tests showed no significant differences in sex and age between DS and non-DS patients, respectively ( $P$ value $>0.05$ ).

Table 2

Demographic characteristics and peripheral blood counts in APL patients with and without

\begin{tabular}{|lllll|}
\hline \multicolumn{1}{l}{ Non-DS } & Ds & Total & P Value \\
\hline Men & 63 & 7 & 70 & 0.7 \\
\hline Women & 50 & 10 & 60 & \\
\hline Age & $35 \pm 13$ & $38.5 \pm 15$ & $36.13 \pm 5.35$ & 0.3 \\
\hline Hb & $9.2 \pm 2.6$ & $8 \pm 1.7$ & $9.2 \pm 4.6$ & 0.4 \\
\hline WBC $\times 10^{3}$ & $65.51 \pm 12.23$ & $61.33 \pm 9.87$ & $64.19 \pm 9.96$ & 0.6 \\
\hline PLT $\times 10^{3}$ & $76.2 \pm 51.6$ & $44.9 \pm 33.7$ & $73.15 \pm 42.6$ & 1.3 \\
\hline Values presented as mean $( \pm$ SD $)$, Hb: Hemoglobin, WBC: White Blood Cells, PLT: Platelet \\
\hline
\end{tabular}

\section{Electrophoresis results}

Electrophoresis results are presented in (Figure 1). The product of tetra ARMS-PCR for rs 1360485 contained three fragments in heterozygote samples (433bp, $284 \mathrm{bp}$ (G allele) and 205bp (A allele)). Two fragments of 433bp and 284bp were seen in the GG mutant homozygous samples, and the AA homozygous 
samples contained 433bp and 25bp fragments (Figure 1. A). In rs2249825, heterozygous samples contained 481bp, 293bp (G) and 245bp (C) fragments. The CC homozygous wild type contained two fragments of $481 \mathrm{bp}$ and $245 \mathrm{bp}$ and the GG homozygous mutant type contained two fragments of $481 \mathrm{bp}$ and $293 \mathrm{bp}$ (Figure 1. B). In rs 1060348 , heterozygous samples contained three fragments of $267 \mathrm{bp}, 189 \mathrm{bp}$ (C) and 132bp (T). CC homozygous wild samples contained two fragments of 267bp and 189bp and TT homozygous mutant samples contained tow fragments of 267bp and 132bp (Figure1. C).

\section{Distribution Of Genotype And Allele Frequency}

In APL patients with and without DS and normal subjects, the most frequent allele was adenine (A) in rs1360485 and cytosine (C) in rs2249825. The most frequent allele was cytosine (C) in rs1060348. The most frequent genotypes for rs1360485 were AA, AG, and GG in the stated order. The most frequent genotype for rs 2249825 was CC followed by CG and GG. The most frequent genotype for rs 1060348 was CC followed by CT. The genotype frequency of rs 1360485 was AA: $69 \%$, AG: $27 \%$ and GG $4 \%$ in APL patients without DS and AA:71\% and AG: $29 \%$ in APL patients with DS. Genotype frequencies for rs2249825 were CC: $73 \%$, CG: $22 \%$, and GG: $5 \%$ in APL patients without DS. In DS patients, genotype frequencies for rs 2249825 were CC: $71 \%$ and CG: $29 \%$. CC: $95 \%$ was the most and CT: $5 \%$ was the least frequent genotype of rs 1060348 in APL patients without DS. In DS patients, CC was seen in all patients (100\%). In healthy subjects, the A allele was more frequent than the $\mathrm{G}$ allele in rs 1360485 . The A allele was seen in $78 \%$ and the $\mathrm{G}$ allele was seen in $22 \%$ of the healthy subjects. The AA, AG, and GG genotype was seen in $60 \%, 35 \%$, and $5 \%$, respectively. The $\mathrm{C}$ allele was more frequent than the $\mathrm{G}$ allele in rs 2249825 polymorphism. The $\mathrm{C}$ allele was detected in $78 \%$ and the $\mathrm{G}$ allele was seen in $22 \%$ of the samples. The genotype frequency of CC, CG, and GG was $61 \%, 33 \%$, $6 \%$, respectively. In rs 1060348 , the C allele (96) was more frequent than the T (4) allele. The most frequent genotype in rs 1360485 was AA in $92 \%$ followed by AG in $8 \%$. None of the samples had a GG genotype. The allele and genotype frequency of HMGB1 polymorphisms are demonstrated in (Table 3 ).

Table 3

HMGB1 polymorphisms allele and genotype frequency in APL patients and healthy people

\begin{tabular}{|c|c|c|c|c|c|c|c|c|c|c|c|c|}
\hline \multicolumn{5}{|c|}{ APL patients without DS } & \multicolumn{4}{|c|}{ APL patients with DS } & \multicolumn{4}{|c|}{ Healthy people } \\
\hline rs number & Genotype & $\begin{array}{l}\text { Genotype } \\
\text { frequency } \\
\%\end{array}$ & $\begin{array}{l}\text { Allele } \\
(\mathrm{N})\end{array}$ & $\begin{array}{l}\text { Allele } \\
\text { frequency } \\
\%\end{array}$ & Genotype & $\begin{array}{l}\text { Genotype } \\
\text { frequency } \\
\%\end{array}$ & $\begin{array}{l}\text { Allele } \\
(\mathrm{N})\end{array}$ & $\begin{array}{l}\text { Allele } \\
\text { frequency } \\
\%\end{array}$ & Genotype & $\begin{array}{l}\text { Genotype } \\
\text { frequency } \\
\%\end{array}$ & $\begin{array}{l}\text { Allele } \\
(\mathrm{N})\end{array}$ & $\begin{array}{l}\text { Allele } \\
\text { frequency } \\
\%\end{array}$ \\
\hline \multirow[t]{3}{*}{ rs1360485 } & AA & 69 & \multirow{2}{*}{$\begin{array}{l}\text { A } \\
(186)\end{array}$} & 82 & $A A$ & 71 & \multirow{2}{*}{$\begin{array}{l}\text { A } \\
(29)\end{array}$} & 85 & AA & 60 & \multirow{2}{*}{$\begin{array}{l}\text { A } \\
(155)\end{array}$} & 78 \\
\hline & AG & 27 & & 18 & AG & 29 & & 18 & AG & 35 & & 22 \\
\hline & GG & 4 & $\begin{array}{l}\text { G } \\
(40)\end{array}$ & & GG & 0 & G (5) & & GG & 5 & $\begin{array}{l}\text { G } \\
(45)\end{array}$ & \\
\hline \multirow[t]{3}{*}{ rs2249825 } & $\mathrm{CC}$ & 73 & \multirow{2}{*}{$\begin{array}{l}\text { C } \\
(189)\end{array}$} & 84 & $\mathrm{CC}$ & 71 & $\begin{array}{l}\text { C } \\
(29)\end{array}$ & 85 & $\mathrm{CC}$ & 61 & \multirow{2}{*}{$\begin{array}{l}C \\
(155)\end{array}$} & 78 \\
\hline & CG & 22 & & 16 & CG & 29 & \multirow{2}{*}{ G (5) } & 15 & CG & 33 & & 22 \\
\hline & GG & 5 & $\begin{array}{l}\text { G } \\
(37)\end{array}$ & & GG & 0 & & & GG & 6 & $\begin{array}{l}\text { G } \\
(45)\end{array}$ & \\
\hline \multirow[t]{3}{*}{ rs1060348 } & $\mathrm{CC}$ & 95 & $\begin{array}{l}\mathrm{C} \\
(220)\end{array}$ & 97 & $\mathrm{CC}$ & 100 & \multirow{2}{*}{$\begin{array}{l}C \\
(34)\end{array}$} & 100 & $\mathrm{CC}$ & 92 & \multirow{2}{*}{$\begin{array}{l}\text { C } \\
(192)\end{array}$} & 96 \\
\hline & CT & 5 & \multirow{2}{*}{$\mathrm{T}(6)$} & 3 & CT & 0 & & 0 & CT & 8 & & 4 \\
\hline & TT & 0 & & & TT & 0 & $\mathrm{~T}(0)$ & & TT & 0 & $\mathrm{~T}(8)$ & \\
\hline
\end{tabular}

Table 4. Analysis of association of HMGB1 polymorphism (rs1360485 and rs2249825) with the development of DS in APL patients

rs1360485 


\begin{tabular}{|c|c|c|c|c|c|c|c|}
\hline Models & Genotype & With DS (\%) & Without DS (\%) & OR95)®\%CID) & P-value & $\mathrm{AlCD}$ & $\mathrm{BIC}$ \\
\hline \multirow[t]{4}{*}{ Codominant } & AA & $12(70.6)$ & 78 (69) & 1 & \multirow[t]{4}{*}{0.47} & \multirow[t]{4}{*}{107.2} & \multirow[t]{4}{*}{118.7} \\
\hline & $A G$ & $5(29.4)$ & $30(2.6)$ & 0.95 & & & \\
\hline & & & & $(0.31-2.96)$ & & & \\
\hline & GG & 0 & $5(4.4)$ & 0 & & & \\
\hline \multirow[t]{3}{*}{ Dominant } & AA & $12(70.6)$ & 78 (69) & 1 & \multirow[t]{3}{*}{0.85} & \multirow[t]{3}{*}{106.7} & \multirow[t]{3}{*}{115.3} \\
\hline & $A G-G G$ & $5(29.4)$ & $35(31)$ & 1.11 & & & \\
\hline & & & & $(0.36-3.43)$ & & & \\
\hline \multirow[t]{2}{*}{ Recessive } & $A A-A G$ & $17(100)$ & 108 (95.6) & 1 & \multirow[t]{2}{*}{0.22} & \multirow[t]{2}{*}{105.2} & \multirow[t]{2}{*}{113.8} \\
\hline & GG & 0 & $5(4.4)$ & 0 & & & \\
\hline \multirow[t]{3}{*}{ Overdominant } & AA-GG & $12(70.6)$ & $83(73.5)$ & 1 & \multirow[t]{3}{*}{0.83} & \multirow[t]{3}{*}{106.7} & \multirow[t]{3}{*}{115.3} \\
\hline & $A G$ & $5(29.4)$ & $30(26.6)$ & 0.89 & & & \\
\hline & & & & $(0.29-2.74)$ & & & \\
\hline \multirow[t]{3}{*}{ Log-additive } & - & - & - & 1.27 & \multirow[t]{2}{*}{0.63} & \multirow[t]{2}{*}{106.5} & \multirow[t]{2}{*}{115.1} \\
\hline & & & & $(0.47-3.44)$ & & & \\
\hline & rs2249825 & & & & & & \\
\hline Models & Genotype & With DS (\%) & Without Ds (\%) & OR95)『\%(ID) & P-value & $\mathrm{AlC} \square$ & $\mathrm{BICl}$ \\
\hline \multirow[t]{4}{*}{ Codominant } & $\mathrm{CC}$ & $12(70.6)$ & $82(72.6)$ & 1 & \multirow[t]{4}{*}{0.35} & \multirow[t]{4}{*}{106.6} & \multirow[t]{4}{*}{118.1} \\
\hline & CG & $5(29.4)$ & $25(22.1)$ & 0.73 & & & \\
\hline & & & & $(0.23-2.82)$ & & & \\
\hline & GG & 0 & $6(5.3)$ & 0 & & & \\
\hline \multirow[t]{3}{*}{ Dominant } & $\mathrm{CC}$ & $12(70.6)$ & $82(72.6)$ & 1 & \multirow[t]{3}{*}{0.88} & \multirow[t]{3}{*}{106.7} & \multirow[t]{3}{*}{115.3} \\
\hline & CG-GG & $5(29.4)$ & 31 (27.4) & 0.92 & & & \\
\hline & & & & $(0.30-2.82)$ & & & \\
\hline \multirow[t]{2}{*}{ Recessive } & CC-CG & $17(100)$ & 107 (94.7) & 1 & \multirow[t]{2}{*}{0.18} & 104.9 & 113.5 \\
\hline & GG & 0 & $6(5.3)$ & 0 & & & \\
\hline overdominant & CC-GG & $12(70.6)$ & $88(77.8)$ & 1 & 0.51 & 106.3 & 114.9 \\
\hline & CG & $5(29.4)$ & $25(22.1)$ & 0.68 & & & \\
\hline & & & & $(0.22-2.11)$ & & & \\
\hline Log-additive & - & - & - & 1.13 & 0.79 & 106.6 & 115.2 \\
\hline & & & & $(0.44-2.93)$ & & & \\
\hline
\end{tabular}

\section{Correlation of HMGB1 gene polymorphisms with differentiation syndrome in APL patients}

We further analyzed the association between the rs1360485, rs2249825 and rs1060348 polymorphisms and the risk of DS under five genetic models (codominant, dominant, recessive, over dominant and log-additive) in APL patients treated with ATRA and ATO using multi variant logistic regression analysis to estimate the $\mathrm{OR}$ and $95 \% \mathrm{Cl}$ of this association. Based on five genetic models used, there was no significant association between rs 1360485 , rs 2249825 and rs1060348 HMGB1 polymorphisms and DS (P value > 0.5). Five genetic models that were used to study rs1360485 and rs2249825 are shown in (Table 4). The results showed no significant association between rs1060348 and DS development based on genetic models (data not shown).

\section{Discussion}

DS is an inflammatory and life-threatening disease with an unknown pathogenesis which may occur in some patients with APL undergoing differentiating treatment with ATRA and ATO [26]. The results of the genetic models in the present study revealed that there were no significant associations between HMGB1 SNPs (rs1360485, rs2249825 and rs1060348) and DS susceptibility in APL patients. However, several studies have indicated the role of HMGB1 in progression of inflammatory diseases $[16,18,19,21,27,28]$. Tang et al found HMGB1 stimulated inflammatory cytokines such as TNF-a and IL1- $\beta$ secretion by MEK/ERK 
signaling and led inflammation in DS [27]. It has been demonstrated that some HMGB1 polymorphisms play an important role in inflammatory diseases and cancers. Wang et al found that the presence of the $\mathrm{G}$ allele in rs2249825 reduced HMGB1 gene expression and was associated with a lower risk of rheumatoid arthritis [16]. In 2015, Jin et al reported that rs2249825 C/G SNP increased the expression of HMGB1 and led to recurrent pregnancy loss HMGB1 as an inflammatory protein is present in chorionic villi and inflammation in chorionic villi can cause recurrent pregnancy loss [19]. The other study indicated that the presence of one $\mathrm{G}$ allele in rs1360485 and one $\mathrm{G}$ allele in rs2249825 increased the risk of breast cancer development [18]. Severe systemic inflammations may result in systemic inflammatory response syndrome (SIRS). The underlying mechanism of the disease is not well understood but Kornbilt et al showed some HMGB1 gene polymorphism affect the mortality. They found that the presence of rs1060348 (982 C>T) in exone 4 of the HMGB1 gene decreased the serum concentration of HMGB1 and was associated with SIRS development and patient survival [28]. In addition, Coa revealed that rs1360485 polymorphism plays role in neonatal necrotizing enterocolitis in Chinese neonates [29]. The results of the present study showed that the A allele was more frequent in the rs1360485 SNP and the $C$ allele was more frequent in rs2240825 and rs1060348 SNPs in APL patients.

\section{Conclusion}

DS symptoms are not specific and different criteria are used to diagnose this complication. In the present study, strict diagnostic criteria were used to select DS patient, which limited the DS population and could have influenced the results. In summary, based on the results, the HMGB1 polymorphisms probably are not associated with DS development in APL patients treated with ATRA and ATO, however, larger studies are required to confirm our results.

\section{Declarations}

\section{Acknowledgements}

This study was supported by Hematology, Oncology, and Stem Cell Transplantation Research Center and Allied School of Medical Sciences of Tehran University of Medical Sciences.

\section{Compliance with Ethical Standards}

Funding: Not applicable

\section{Ethical approval}

All procedures performed in studies involving human participants were in accordance with the ethical standards of national research committee and with the 1964 Helsinki declaration and its later amendments or comparable ethical standards. This article does not contain any studies with animals performed by any of the authors.

\section{Informed consent}

Informed consent was obtained from all individual participants included in the study

\section{References}

1. de Thé $H$ (2018) Differentiation therapy revisited. Nat Rev Cancer 18: 117-27.

2. Deschler B, Lübbert M (2006) Acute myeloid leukemia: epidemiology and etiology. Cancer 107: 2099-107.

3. Wang Z-Y, Chen Z (2008) Acute promyelocytic leukemia: from highly fatal to highly curable. Blood 111: 2505-15.

4. Dore Al, Santana-Lemos BA, Coser VM, Santos FL, Dalmazzo LF, Lima AS, et al (2007) The association of ICAM-1 Exon 6 (E469K) but not of ICAM-1 Exon 4 (G241R) and PECAM-1 Exon 3 (L125V) polymorphisms with the development of differentiation syndrome in acute promyelocytic leukemia. Journal of leukocyte biology 82: 1340-3.

5. Luesink M, Pennings JL, Wissink WM, Linssen PC, Muus P, Pfundt R, et al (2009) Chemokine induction by all-trans retinoic acid and arsenic trioxide in acute promyelocytic leukemia: triggering the differentiation syndrome. Blood 114: 5512-21.

6. Ryan MM (2018) Acute Promyelocytic Leukemia: A Summary. J Adv Pract Oncol 9: 178-87.

7. Tsai W, Shih C, Lin C, Ho C, Hsu F, Hsu H (2008) MCP-1 in the migration of differentiated leukemic cells toward alveolar epithelial cells. European Respiratory Journal 2008.

8. Rogers JE, Yang D (2012) Differentiation syndrome in patients with acute promyelocytic leukemia. J Oncol Pharm Pract 18: 109-14.

9. Montesinos P, Sanz MA (2011) The differentiation syndrome in patients with acute promyelocytic leukemia: experience of the pethema group and review of the literature. Mediterr J Hematol Infect Dis 3: e2011059.

10. Jimenez JJ, Chale RS, Abad AC, Schally AV (2020) Acute promyelocytic leukemia (APL): a review of the literature. Oncotarget 11: $992-1003$.

11. Montesinos P, Bergua JM, Vellenga E, Rayón C, Parody R, de la Serna J, et al (2009) Differentiation syndrome in patients with acute promyelocytic leukemia treated with all-trans retinoic acid and anthracycline chemotherapy: characteristics, outcome, and prognostic factors 113: 775-83.

12. Rego EM, De Santis GC (2011) .Differentiation syndrome in promyelocytic leukemia: clinical presentation, pathogenesis and treatment. Mediterr J Hematol Infect Dis 3: e2011048.

13. Stahl M, Tallman MS (2019) Differentiation syndrome in acute promyelocytic leukaemia. British journal of haematology 187: 157-62. 
14. Kianian F, Kadkhodaee M, Sadeghipour HR, Karimian SM, Seifi B (2020) An overview of high-mobility group box 1, a potent pro-inflammatory cytokine in asthma. J Basic Clin Physiol Pharmacol 31.

15. Jiang M, Li X, Quan X, Li X, Zhou B (2018) Single Nucleotide Polymorphisms in HMGB1 Correlate with Lung Cancer Risk in the Northeast Chinese Han Population. Molecules (Basel, Switzerland) 23.

16. Wang LH, Wu MH, Chen PC, Su CM, Xu G, Huang CC, et al (2017) Prognostic significance of high-mobility group box protein 1 genetic polymorphisms in rheumatoid arthritis disease outcome. Int J Med Sci 14: 1382-8.

17. Qiu P, Wang L, Ni J, Zhang Y (2019) Associations between HMGB1 gene polymorphisms and susceptibility and clinical outcomes in Chinese Han sepsis patients. Gene 687:23-9.

18. Huang BF, Tzeng HE, Chen PC, Wang CQ, Su CM, Wang Y, et al (2018) HMGB1 genetic polymorphisms are biomarkers for the development and progression of breast cancer. International journal of medical sciences 15: 580-6.

19. Jin H, Wu J, Yang Q, Cai Y, He W, Liu C (2015) High mobility group box 1 protein polymorphism affects susceptibility to recurrent pregnancy loss by upregulating gene expression in chorionic villi. J Assist Reprod Genet 32:1123-8.

20. Wang Y, Li XP, Yin JY, Zhang Y, He H, Qian CY, et al (2014) Association of HMGB1 and HMGB2 genetic polymorphisms with lung cancer chemotherapy response. Clin Exp Pharmacol Physiol 41: 408-15

21. Kornblit B, Munthe-Fog L, Madsen HO, Strøm J, Vindeløv L, Garred P (2008) Association of HMGB1 polymorphisms with outcome in patients with systemic inflammatory response syndrome. Crit Care 12: R83.

22. Yuan S, Liu Z, Xu Z, Liu J, Zhang J (2020) High mobility group box 1 (HMGB1): a pivotal regulator of hematopoietic malignancies. J Hematol Oncol 13: 91.

23. Ulloa L, Messmer D (2006) High-mobility group box 1 (HMGB1) protein: friend and foe. Cytokine Growth Factor Rev 17: $189-201$.

24. Magna M, Pisetsky DS (2014) The role of HMGB1 in the pathogenesis of inflammatory and autoimmune diseases. Mol Med 20:138-46.

25. Mohammadzadeh Z, Omidkhoda A, Chahardouli B, Hoseinzadeh G, Moghaddam KA, Mousavi SA, et al (2021) The impact of ICAM-1, CCL2 and TGM2 gene polymorphisms on differentiation syndrome in acute promyelocytic leukemia. BMC Cancer 21: 46.

26. Cardinale L, Asteggiano F, Moretti F, Torre F, Ulisciani S, Fava C, et al (2014) Pathophysiology, clinical features and radiological findings of differentiation syndrome/all-trans-retinoic acid syndrome. World J Radiol 6: 583-8.

27. Tang L, Chai W, Ye F, Yu Y, Cao L, Yang M, et al (2017) HMGB1 promotes differentiation syndrome by inducing hyperinflammation via MEK/ERK signaling in acute promyelocytic leukemia cells. Oncotarget 8: 27314-27.

28. Goodwin GH, Sanders C, Johns EW (1973) A new group of chromatin-associated proteins with a high content of acidic and basic amino acids. Eur J Biochem 38: 14-9.

29. Cao H, Guo D (2021) Association of High-Mobility Group Box 1 (HMGB1) Gene Polymorphisms with Susceptibility and Better Survival Prognosis in Chinese Han Neonatal Necrotizing Enterocolitis. Med Sci Monit 27:e930015.

\section{Figures}
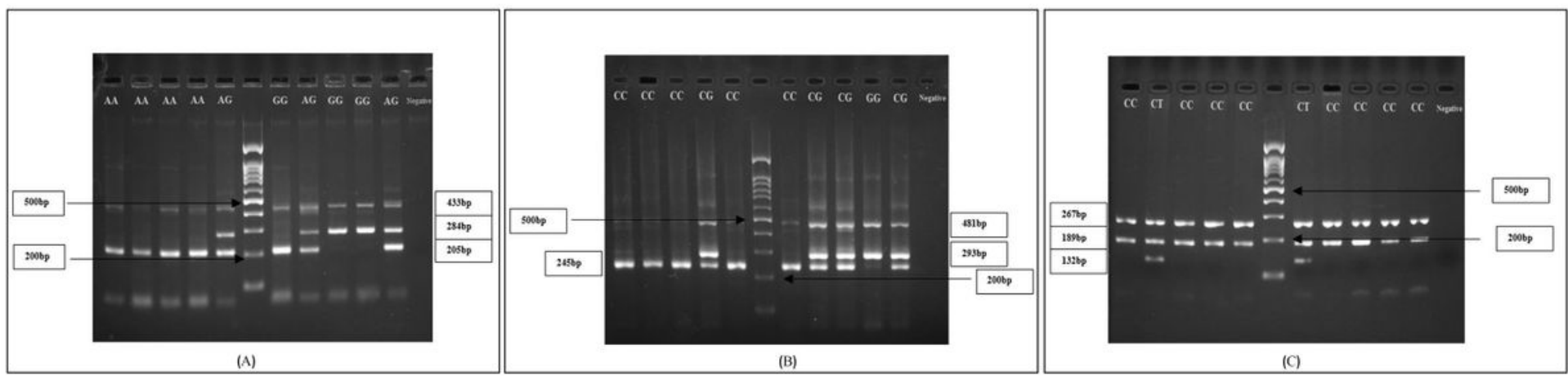

Figure 1

Agarose gel electrophoresis of Tetra primer ARMS PCR. Genotype variation of rs1360485 determined by control fragment (433bp), specific fragment of G allele (284bp) and A allele (205bp). Samples with three 433bp, 284bp and 205bp bands are AG heterozygote, samples with two bands $433 \mathrm{bp}$ and $284 \mathrm{bp}$ are GG homozygote and samples which contains two band 433bp and 205bp are AA homozygote samples (A). Genotype variation of rs2249825 determined by control fragment (481bp), specific fragment of G allele (293bp) and C allele (245bp). sequencing result of heterozygote genotype TG. Samples includes three $481 \mathrm{bp}, 293 \mathrm{bp}$ and $245 \mathrm{bp}$ are CG heterozygote samples. Samples with two $481 \mathrm{bp}$ and $293 \mathrm{bp}$ bands are GG homozygote samples and samples with $481 \mathrm{bp}$ and $245 \mathrm{bp}$ bands are CC heterozygote samples (B). Genotype variation of rs 1060348 determined by control fragment (267bp), specific fragment of $\mathrm{C}$ allele (189bp) and T allele (132bp). Samples contain three bands, 267bp, 189bp and 132bp are heterozygote. Samples with 267bp and 189bp bands are CC homozygote samples and samples with two $267 \mathrm{bp}$ and $132 \mathrm{bp}$ bands are TT homozygotes (C). 